\title{
Bone Marrow Stroma Damage Induced by Chemotherapy for Acute Lymphoblastic Leukemia in Children
}

\author{
FRANCIS CORAZZA, CHRISTOPHE HERMANS, ALINA FERSTER, PIERRE FONDU, \\ ANNE DEMULDER, AND ERIC SARIBAN
}

Laboratory of Hematology, Brugmann University Hospital, 1020 Brussels, Belgium [F.C., P.F., A.D.];

Hematology-Oncology Unit, Hôpital Universitaire des Enfants [C.H., A.F., E.S.], 1090 Brussels, Belgium

\begin{tabular}{|c|c|}
\hline \multicolumn{2}{|c|}{ ABSTRACT } \\
\hline $\begin{array}{l}\text { Several studies have suggested a role of bone marrow stroma } \\
\text { injury in long-term chemotherapy-induced hematopoietic fail- } \\
\text { ure. To evaluate whether bone marrow microenvironment is } \\
\text { altered by chemotherapy for acute lymphoblastic leukemia } \\
\text { (ALL) and to determine its contribution to postchemotherapy } \\
\text { anemia, we investigated the ability of stroma from children } \\
\text { receiving maintenance chemotherapy for ALL to support hema- } \\
\text { topoiesis. Long-term bone marrow cultures (LTBMC) were es- } \\
\text { tablished with bone marrow cells either from ALL children under } \\
\text { therapy ( } n=24 \text { ) or from control subjects ( } n=19 \text { ). Nonadherent } \\
\text { cells and colony forming units-granulocytic monocytic (CFU- } \\
\text { GM) output in LTBMC did not differ between patients and } \\
\text { controls. In contrast, burst forming unit-erythroid (BFU-E) num- } \\
\text { bers were lower in patient LTBMC ( } p=0.013 \text { ). Co-cultures of } \\
\text { normal CD34 cells and preformed patient or control stromas } \\
\text { showed significantly reduced hematopoietic supportive capabil- } \\
\text { ities of patient stromas: both CFU-GM and BFU-E were reduced } \\
\text { ( } p=0.002 \text { and } 0.046 \text {, respectively). In addition, supernatants } \\
\text { (SN) of patients' LTBMC inhibited normal BFU-E growth com- } \\
\text { pared with SN of normal LTBMC. Transforming growth factor } \\
\text { (TGF)- } \beta 1 \text { levels were increased in patient cultures ( } p=0.0039 \text { ) } \\
\text { and inversely correlated with BFU-E produced in LTBMC }(r= \\
-0.36, p=0.04 \text { ). Neutralization of TGF- } \beta 1 \text { significantly in- } \\
\text { creased the BFU-E output of patient LTBMC ( } p=0.0078 \text { ). In } \\
\text { contrast, macrophage inflammatory peptide (MIP)- } 1 \alpha \text { levels }\end{array}$ & $\begin{array}{l}\quad \text { Abbreviations } \\
\text { ALL, acute lymphoblastic leukemia } \\
\text { BFU-E, burst forming unit-erythroid } \\
\text { CFU-GM, colony forming unit-granulocytic monocytic } \\
\text { CT, chemotherapy } \\
\text { EORTC, European Organization for Research and Treatment } \\
\text { of Cancer } \\
\text { IFN- } \boldsymbol{\gamma} \text {, interferon } \gamma \\
\text { LTBMC, long-term bone marrow culture } \\
\text { MIP-1 } \boldsymbol{\alpha} \text {, macrophage inflammatory peptide } 1 \alpha \\
\text { PE, phycoerythrin } \\
\text { PMN, polymorphonuclear } \\
\text { RhEPO, recombinant human erythropoietin } \\
\text { SDF-1 } \alpha \text {, stromal-derived factor } 1 \alpha \\
\text { SN, supernatant } \\
\text { TGF- } \boldsymbol{\beta} 1 \text {, transforming growth factor } \beta 1 \\
\text { TNF- } \boldsymbol{\alpha} \text {, tumor necrosis factor } \alpha\end{array}$ \\
\hline
\end{tabular}

Hematopoiesis requires cooperation between progenitors and a variety of functionally and phenotypically different cell types that form the bone marrow stroma. Altered hematopoietic functions have been reported after the clinical use of a

Received September 26, 2002; accepted May 27, 2003.

Correspondence: Francis Corazza, M.D., Laboratory of Hematology, CHU-Brugmann, 4 Place Van Gehuchten, 1090 Brussels, Belgium; e-mail address: francis.corazza@ulb.ac.be

Supported by grant 7.4559.99 from "Télévie," Belgian National Scientific Research Fund (FNRS) and by grants from Lambeau-Marteau, Wacjmann-Mandelbaum, and D \& A Van Buuren Foundations, and the Foundation "Aide aux Enfants Atteints d'un Cancer," Luxemburg.

DOI: 10.1203/01.PDR.0000099773.71438.91 variety of chemotherapeutic agents (1-6). The mechanisms of this CT-induced bone marrow injury are unclear. The most primitive hematopoietic stem cells responsible for lifelong marrow reconstitution are not normally targets of CT, being quiescent under ordinary circumstances. Nevertheless, quantitative and qualitative impairment of stem cells has been demonstrated to persist a long time after the end of the treatment (7). After high-dose cytotoxic therapy and/or radiation exposure, the stroma may be seriously damaged $(8,9)$ and the hematopoietic defects observed might be the result of CTinduced stromal lesions $(9,10)$. In this regard, we have previously observed a defect in erythropoietic activity in children 
under CT for ALL. In these children, anemia was strongly correlated with a decreased erythropoietic progenitor pool, as indicated by a low level of soluble transferrin receptor, despite an adequate increase in erythropoietin production in response to the anemia (11).

The aim of this study was to evaluate whether bone marrow stroma is altered during maintenance CT for ALL and to evaluate its contribution to postchemotherapy cytopenia and anemia. We found a decreased number of erythroid progenitors in LTBMC during maintenance CT, whereas the number of granulocytic progenitors was otherwise normal. We thus investigated the mechanisms of this selective erythropoiesis impairment. Co-culture experiments using purified normal $\mathrm{CD} 4^{+}$cells and stromal cells either from normal controls or from patients indicated a defective stromal cell function. Because a variety of inflammatory cytokines released from microenvironment may play a role in acute hematopoietic toxicity induced by a variety of chemotherapeutic agents, we further investigated whether cytokines known to inhibit erythropoiesis were involved in the erythroid defect observed in patients under $\mathrm{CT}$. We found an increase in the growth-inhibiting factor TGF- $\beta 1$, together with a decrease in the chemoprotective factor MIP-1 $\alpha$. Such functional deregulation within stromal cells might contribute in part to acute and chronic CTassociated hematopoietic toxicities $(12,13)$.

\section{MATERIALS AND METHODS}

Patient and normal bone marrow specimens. LTBMC were established with bone marrow mononuclear cells obtained at time of follow-up in 24 consecutive ALL children under maintenance $\mathrm{CT}$. The mean time since diagnosis was $23 \pm 11$ mo. All patients were in first complete remission after treatment without central nervous radiotherapy according to the clinical trials conducted by the Children Leukemia Cooperative Group from EORTC (14). Maintenance CT consisted of daily oral 6-mercaptopurine and methotrexate once a week. Control LTBMC were conducted simultaneously using bone marrow cells either from normal adults or from children undergoing orthopedic surgery. After informed consent, BM samples were obtained from the posterior iliac crest, under local anesthesia. Our institutional ethical committee approved the study.

Long-term bone marrow culture. Mononuclear cells isolated by gradient centrifugation (Lymphoprep, Nycomed, Oslo, Norway) were used to establish LTBMC according to Gartner and Kaplan (15) with minor modifications. Mononucleated cells were suspended in $\alpha$-modified Eagle's medium ( $\alpha \mathrm{MEM})$ supplemented with $12.5 \% \mathrm{FCS}, 12.5 \%$ horse serum, $100 \mathrm{U} / \mathrm{mL}$ penicillin-streptomycin (Invitrogen, Carlsbad, CA, U.S.A.) and $10^{-6} \mathrm{M}$ hydrocortisone hemisuccinate (Sigma Chemical, St. Louis, MO, U.S.A.), and seeded in $25 \mathrm{~cm}^{2}$ flasks (Orange Scientific, Braine-l'Alleud, Belgium). At weekly intervals, cultures were fed by replacement of half the culture medium with fresh medium. The nonadherent cells recovered from the SN were counted and assayed in short-term methylcellulose cultures for the presence of CFU-GM and BFU-E. The nonadherent CFU-GM and BFU-E output of individual cultures was determined each week. After 4 wk, the SN was removed, centrifuged, and stored at $-80^{\circ} \mathrm{c}$ for ELISA cytokine assays.

Cytokine neutralization experiments and co-cultures of stromal layers and $\mathrm{CD} 34^{+}$cells were performed in six-well plates, each well containing $4 \mathrm{~mL}$ cell suspension to keep the same cell/surface ratio as in flasks. In these experiments, in addition to nonadherent progenitors, the number of progenitors in the adherent layer was determined after 5-wk culture. To this purpose, the $\mathrm{SN}$ and nonadherent cells were collected and, after two rinses with $\alpha \mathrm{MEM}$, replaced by collagenase $(200 \mathrm{U} / \mathrm{mL}$, Invitrogen). After $1 \mathrm{~h}$ incubation at $37^{\circ} \mathrm{C}$, the cells were washed, counted, and plated for CFU-GM and BFU-E assays.

Progenitor cultures. Approximately $10^{5}$ cells were plated in $1-\mathrm{mL}$ aliquots of $\alpha \mathrm{MEM}$ containing 30\% FCS, $1 \%$ BSA, and $0.9 \%$ methylcellulose. Cultures were stimulated with a mixture of IL-3 $10 \mathrm{ng} / \mathrm{mL}$ and granulocyte-macrophage colony stimulating factor $(40 \mathrm{ng} / \mathrm{mL})$ or rhEPO (Eprex, Janssen-Cilag, Berchem, Belgium) $2 \mathrm{U} / \mathrm{mL}$ for CFU-GM or BFU-E cultures, respectively. Plates were incubated at $37^{\circ} \mathrm{C}$ in a fully humidified atmosphere with $5 \% \mathrm{CO}_{2}$. Colonies were scored on day 14.

Isolation of CD34 ${ }^{+}$cells. $\mathrm{CD}^{+} 4^{+}$cells were prepared from mononuclear cell suspended in PBS with $0.5 \%$ BSA and $2 \mathrm{mM}$ EDTA. CD34 ${ }^{+}$were obtained using magnetic-activated cell separation beads (Miltenyi Biotec, Sunnyvale, CA, U.S.A.) according to the manufacturer's instructions. The percentage of $\mathrm{CD}^{+}{ }^{+}$cells in enriched fractions was determined on a FACScan flow cytometer (BD Biosciences, Erembodegem, Belgium) after staining with PE-conjugated anti-CD34. PElabeled isotype control antibody was used as a negative control (BD Biosciences).

Co-culture of stromal layers with normal $\mathrm{CD}^{+} 4^{+}$cells (two-phase LTBMC). Stromal layers were established in $\alpha$ MEM supplemented with $10 \%$ FCS and $10^{-6}$ M hydrocortisone hemisuccinate. In these conditions, stromal layers develop normally in 4 wk with no residual hematopoietic progenitors (16), avoiding irradiation. Stromal layers were washed and seeded with fresh, normal $\mathrm{CD} 34^{+}$bone marrow cells $\left(10^{4}\right.$ cells $/ \mathrm{mL}$ ). Subsequently, LTBMC were conducted as described above for $5 \mathrm{wk}$ more. Confluent stroma from patients and controls were developed and tested simultaneously in the same experiment with $\mathrm{CD} 34^{+}$cells from two different normal donors.

Cytokine ELISA assays. IL- $1 \alpha$, TNF- $\alpha$, IFN- $\gamma$, IL-6, TGF$\beta 1, \operatorname{MIP}-1 \alpha$, and SDF- $1 \alpha$ were assayed by ELISA (Quantikine Immunoassays, R \& D Systems, Abingdon, UK; TNF- $\alpha$ measured by PeliKine-Compact human TNF- $\alpha$ ELISA kit, Caltag Laboratories, Burlingame, CA, U.S.A.) in LTBMC SN from patients and controls. The assays detected IL- $1 \alpha$ to a sensitivity of $0.5 \mathrm{pg} / \mathrm{mL}$, TNF- $\alpha$ to $6 \mathrm{pg} / \mathrm{mL}$, IFN- $\gamma$ to $3 \mathrm{pg} / \mathrm{mL}$, IL- 6 to $0.7 \mathrm{pg} / \mathrm{mL}$, TGF- $\beta 1$ to $7 \mathrm{pg} / \mathrm{mL}, \mathrm{MIP}-1 \alpha$ to $6 \mathrm{pg} / \mathrm{mL}$, and SDF- $1 \alpha$ to $18 \mathrm{pg} / \mathrm{mL}$.

Assay for erythroid and myeloid growth inhibitory activity in LTBMC SN and neutralization by anti-cytokine antibodies. To detect inhibitory activity in LTBMC SN, normal bone marrow $\mathrm{CD}^{+} 4^{+}$cells $\left(5 \times 10^{3}\right.$ cells $\left./ \mathrm{mL}\right)$ were plated in methylcellulose cultures supplemented with $10 \% \mathrm{SN}$ from normal or patient LTBMC. Controls consisted in culture added 
with SN of a mock LTBMC. In a second series of experiments, short-term progenitor cultures were supplemented with $10 \%$ $\mathrm{SN}$ of LTBMC either untreated or previously incubated for $1 \mathrm{~h}$ with $1 \mu \mathrm{g} / \mathrm{mL}$ anti-TGF- $\beta 1$ neutralizing antibody (R \& D Systems).

Effect of anti-cytokine antibodies on the number of erythroid and myeloid progenitors generated in LTBMC. LTBMC from both patients and controls were conducted simultaneously in standard conditions, or supplemented with anti-human TGF- $\beta 1$ neutralizing antibody $(1 \mu \mathrm{g} / \mathrm{mL})$. The concentration of antibody was sufficient to neutralize $10,000 \mathrm{pg}$ TGF- $\beta 1$. In selected experiments, a control culture was supplemented with a control isotype antibody. There was no difference between standard cultures and nonspecific IgG added cultures. In addition, to determine the role played by MIP- $1 \alpha$, LTBMC from normal or patient bone marrow were supplemented with recombinant MIP-1 $\alpha$ (40 $\mathrm{ng} / \mathrm{mL}, \mathrm{R} \&$ D Systems) or with anti-human MIP- $1 \alpha$ neutralizing antibody in concentration sufficient to neutralize $500 \mathrm{pg} / \mathrm{mL}$ MIP- $1 \alpha$.

Statistical analysis. Results are expressed as mean \pm SEM except when stated otherwise. Significance levels were determined using two-sided $t$ test with or without Welch's correction (Prism, GraphPad Software, San Diego, CA, U.S.A.). $p$ Values $<0.05$ are considered statistically significant.

\section{RESULTS}

LTBMC in patients under maintenance CT for ALL. The cultures initiated with marrow from patients and controls formed a confluent adherent layer with a similar morphology in the same time (3-4 wk for most). The number of total nucleated cells present in the nonadherent fraction was similar in patients and controls for the overall culture period. The number of erythroid progenitors present in LTBMC was markedly reduced in patients beyond the second week of culture. In contrast, CFU-GM numbers were similar in patients and controls (Fig. 1). No difference was observed between adult and pediatric controls (data not shown).

Co-culture of stromal layers with normal CD34 ${ }^{+}$cells (two-stage LTBMC). LTBMC established with patient stromal layers inoculated with normal $\mathrm{CD} 34^{+}$cells generated lower numbers of progenitors, both erythroid and myeloid, than in cultures established with normal stromal layers (mean BFU-E were $27.3 \pm 11.6$ and $72.7 \pm 25.3, p=0.046$; and mean CFU-GM were $1610 \pm 340$ and $3744 \pm 255, p=0.002$, respectively in LTBMC performed on patient or normal stroma (Fig. 2).

Erythroid and myeloid growth inhibitory activity in LTBMC $S N$ and neutralization by anti-cytokine antibodies. The effect of LTBMC SN on normal myeloid and erythroid progenitor growth was tested in progenitor assays using normal bone marrow $\mathrm{CD} 34^{+}$cells. SN of 4-wk-old LTBMC established with patient bone marrow inhibited significantly and selectively the growth of erythroid progenitors from normal bone marrow cultured with SN from normal LTBMC and with patient SN $(35.2 \pm 5.4$ and $16.7 \pm 2.9$ colonies per well, respectively, $p=0.01$ ) (Fig. 3). In contrast, patient SN did not inhibit CFU-GM growth at the same concentration. These
A BFU-E

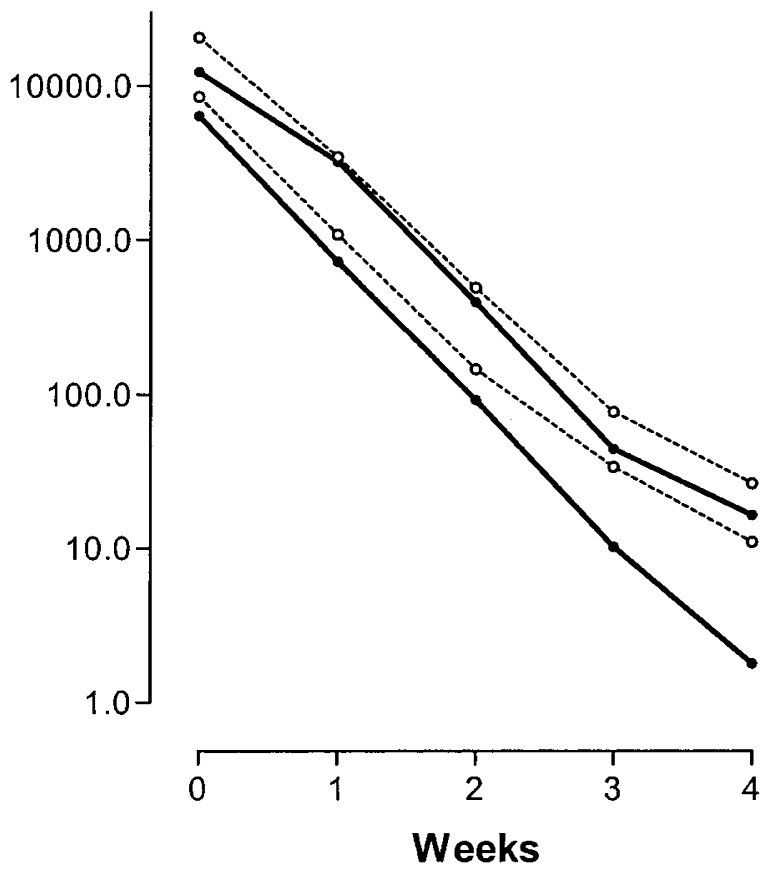

B

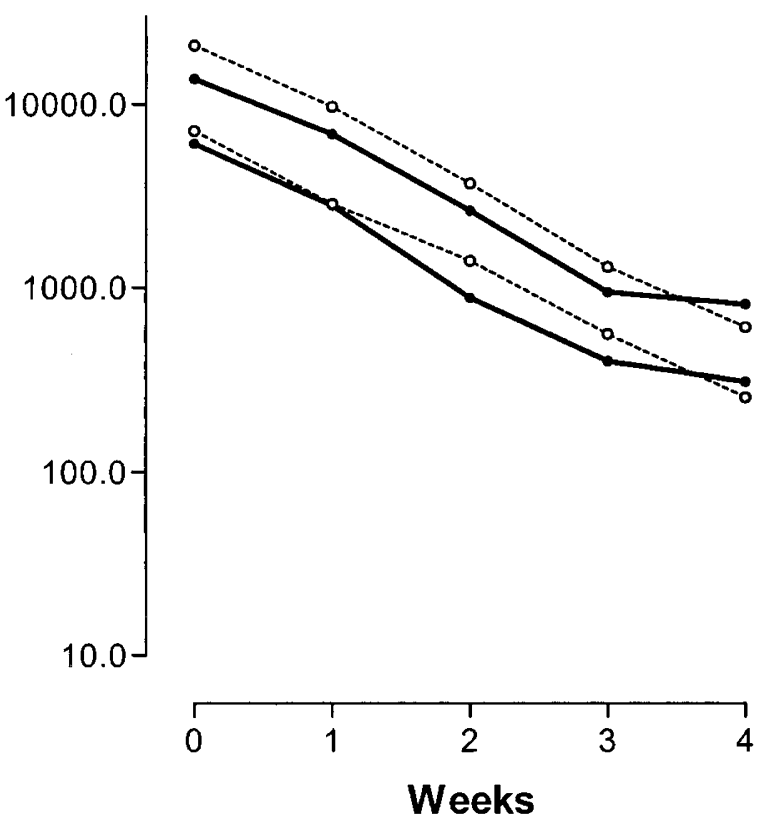

Figure 1. Nonadherent BFU-E and CFU-GM produced in LTBMC from patients and healthy controls. Frequencies of nonadherent BFU-E $(A)$ and CFU-GM $(B)$ generated in LTBMC during the overall culture period. Results shown are $95 \%$ confidence intervals (mean \pm 2 SD) of progenitors levels in patients, $n=24$ (solid line) compared with normal controls, $n=19$ (dashed line). The frequency of BFU-E, but not CFU-GM, is significantly lower in patients than in controls at wk $3(27.2 \pm 8.3$ vs $49.8 \pm 10.8, p=0.047)$ and wk $4(9.1 \pm 3.5$ vs $18.7 \pm 3.7, p=0.013)$. 
A

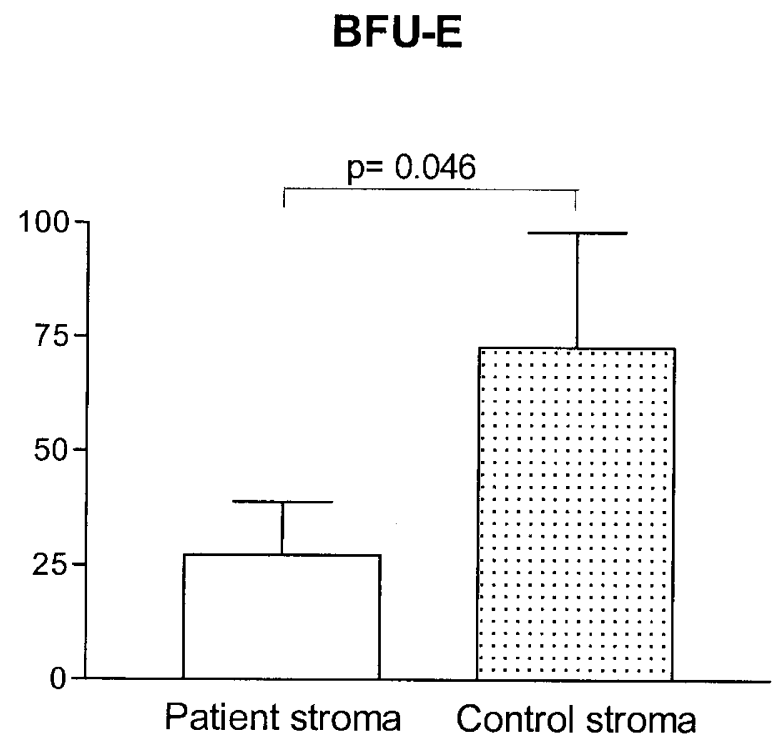

B

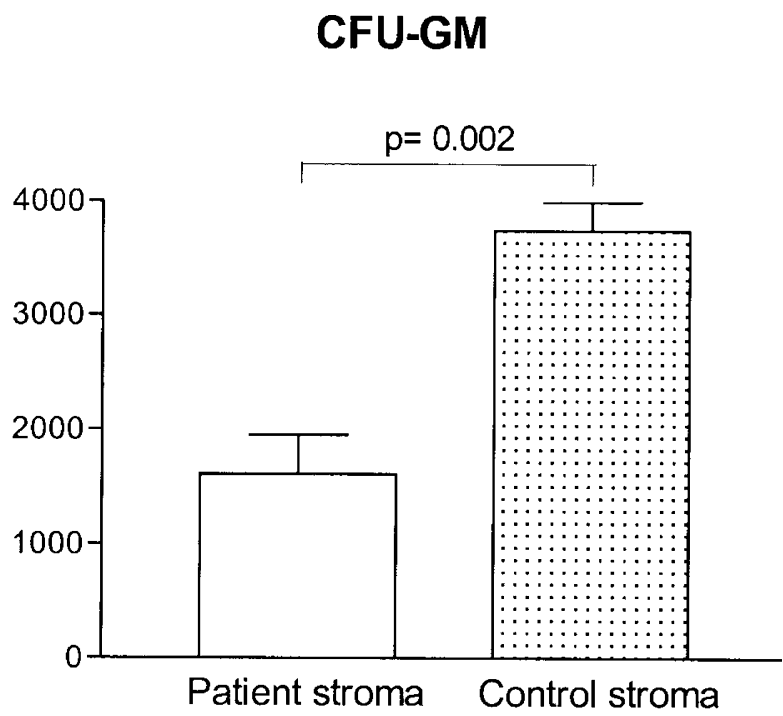

Figure 2. Co-culture of normal $\mathrm{CD}_{3} 4^{+}$bone marrow cells with preestablished normal or patient stromas. Two-stage LTBMC performed by inoculating pre-established confluent stromal layers either from patients $(n=$ 6 ) or normal subjects $(n=7)$ with normal bone marrow $\mathrm{CD} 34^{+}$cells. Each bar represents mean $\pm \mathrm{SEM}$ of cumulative number of progenitors ( $A$ : BFU-E, $B$ : CFU-GM) generated throughout the culture period including those present in the stromal layer at the end of culture.

results suggest that factors released by stromal layers could be responsible for the inhibition of erythroid differentiation in long-term cultures. Accordingly, erythropoiesis inhibitory cytokines known to be released by stromal cells, including IL-6, IL- $1 \alpha$, TNF- $\alpha$, IFN- $\gamma$, SDF- $1 \alpha$, TGF- $\beta 1$, and MIP- $1 \alpha$, were measured in SN from patients and normal LTBMC and in mock culture SN prepared by incubating culture medium in the same conditions without any cells for the same period. Among the cytokines assayed, only TGF- $\beta 1$ and MIP- $1 \alpha$ levels were different in patients compared with controls (Table 1). TGF- $\beta 1$ levels were significantly increased in patient LTBMC and were
A

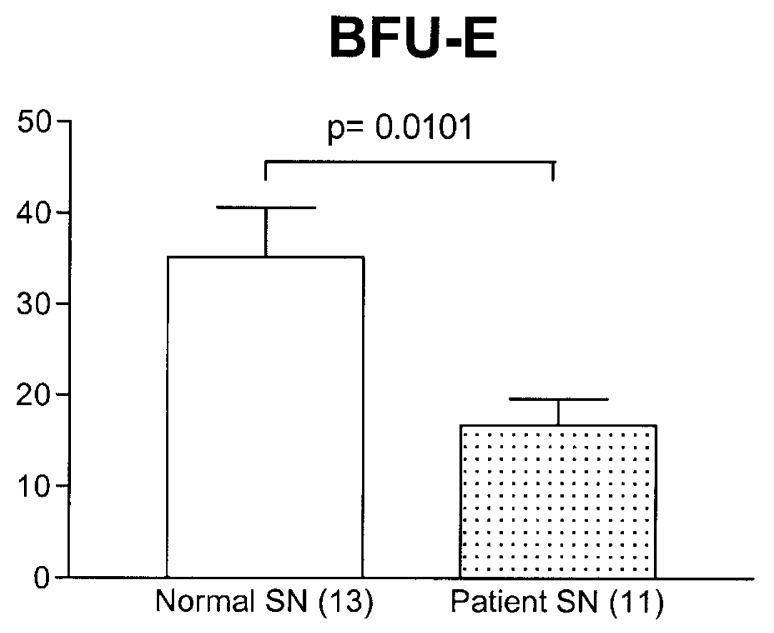

B

CFU-GM

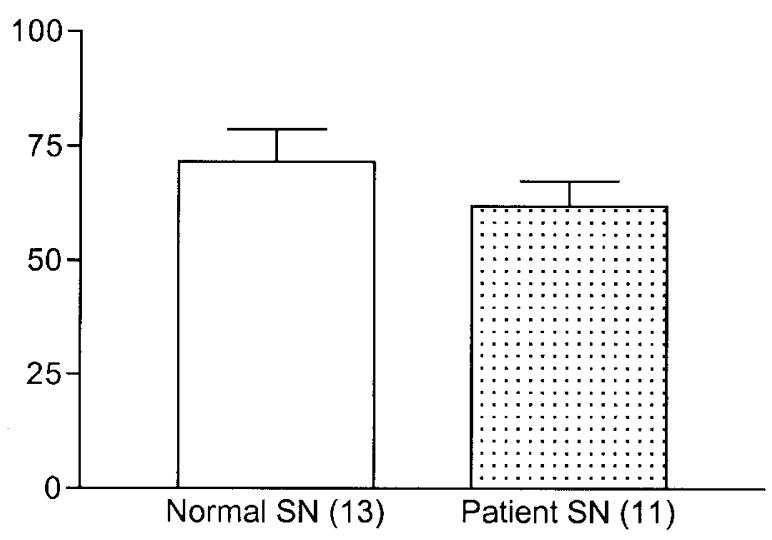

Figure 3. Effect of LTBMC SN on normal erythroid progenitor cell growth. $\mathrm{SN}$ of LTBMC recovered at the end of the 4 th week were added $10 \% \mathrm{vol} / \mathrm{vol}$ to short-term progenitor cultures from normal $\mathrm{CD} 34^{+}$bone marrow cells. Each bar represents the mean \pm SEM colony count (A: BFU-E, $B$ : CFU-GM) obtained from cultures with the individually tested $\mathrm{SN}, 13$ from normal LTBMC, 11 from patient LTBMC (each tested in triplicate).

Table 1. Cytokine concentration in patient and control supernatants

\begin{tabular}{lccc}
\hline $\begin{array}{c}\text { Cytokine/chemokine } \\
(\mathrm{pg} / \mathrm{mL})\end{array}$ & $\begin{array}{c}\text { Patient LTBMC } \\
(n=13)\end{array}$ & $\begin{array}{c}\text { Control LTBMC } \\
(n=16)\end{array}$ & $P$ \\
\hline IL-1 $\alpha$ & Not detectable & Not detectable & \\
IFN- $\gamma$ & $5 \pm 0.2$ & $5 \pm 1.1$ & NS \\
IL-6 & $7118 \pm 1526$ & $9527 \pm 1616$ & NS \\
TNF- $\alpha$ & Not detectable & Not detectable & \\
TGF- $\beta 1$ & $18 \pm 2.5$ & $10 \pm 2.3$ & 0.0039 \\
MIP-1 $\alpha$ & $23 \pm 2$ & $41 \pm 5.9$ & 0.015 \\
SDF-1 $\alpha$ & $6379 \pm 1157$ & $5615 \pm 1401$ & NS \\
\hline
\end{tabular}

negatively correlated with the number of BFU-E present in SN of wk 3 and 4 LTBMC $(r=-0.36, p=0.04)$ (data not shown).

SN of patient and normal LTBMC were treated with antiTGF- $\beta 1$ neutralizing antibody. Immunoassay for TGF- $\beta 1$ con- 
firmed that it was undetectable in all samples after neutralization. The inhibitory effect of SN on normal erythroid progenitors growth was significantly reduced $(p=0.022)$ after neutralization procedure (Fig. 4). The same treatment had no significant effect either on SN of normal LTBMC or on CFU-GM growth.

Effect of anti-TGF-ß1 antibody on erythroid and myeloid progenitors generated in LTBMC. LTBMC from bone marrow cells of six patients and four normal subjects were performed either in standard conditions or with neutralizing antihuman TGF- $\beta 1(1 \mu \mathrm{g} / \mathrm{mL})$ or with a control IgG1. Patient LTBMC in presence of neutralizing anti-TGF- $\beta 1$ antibody showed a moderate but significant increase in the number of BFU-E produced in the overall culture period. BFU-E numbers

A

\section{BFU-E}

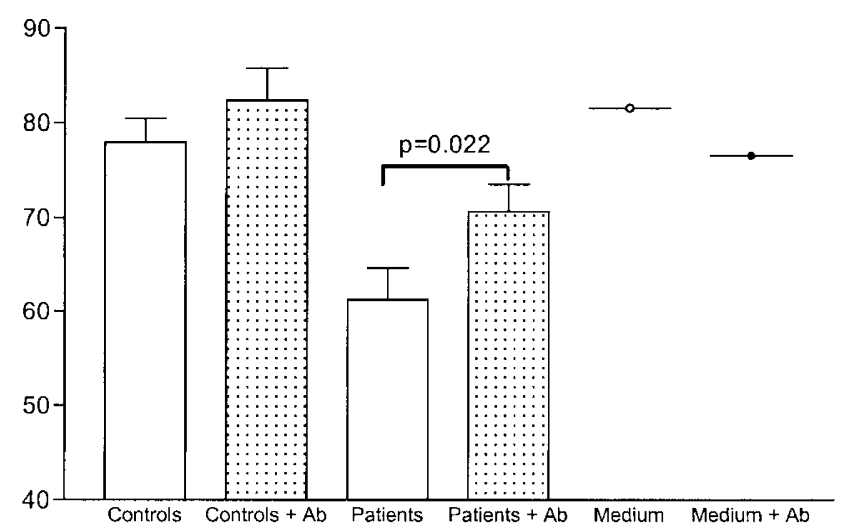

B

\section{CFU-GM}

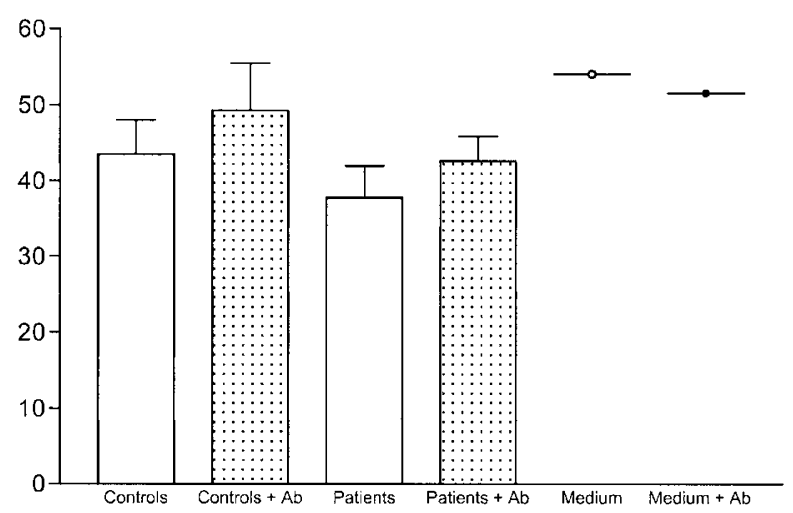

Figure 4. Neutralization of TGF- $\beta 1$ in LTBMC SN. SN from patient ( $n=$ $11)$ and control $(n=13)$ LTBMC were treated for $1 \mathrm{~h}$ either with $\alpha$-MEM alone or with anti-TGF- $\beta 1$ neutralizing antibody. These SN were subsequently added $10 \% \mathrm{vol} / \mathrm{vol}$ to normal bone marrow $\mathrm{CD}_{3} 4^{+}$short-term cultures to determine their effect on normal progenitor growth in the same conditions as in Figure 3. Each bar represents the mean colony numbers \pm SEM for BFU-E $(A)$ and CFU-GM $(B)$. The difference was significant only between BFU-E cultures added with antibody-treated and untreated SN from patient LTBMC. were $302 \pm 106$ and $510 \pm 205$, respectively, in cultures without and with anti-TGF- $\beta 1$ antibody, $p=0.0078$ (Table 2a). The number of CFU-GM in LTBMC was not altered by the addition of anti-TGF- $\beta 1$ antibody.

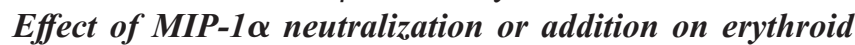
and myeloid progenitors generated in LTBMC. Immunoassays of MIP- $1 \alpha$ in LTBMC SN showed a lower level in cultures from patients than in those from normal subjects. To determine whether this chemokine played a role in the hematopoietic defect observed in patients, LTBMC were either supplemented with recombinant MIP- $1 \alpha(40 \mathrm{ng} / \mathrm{mL})$ or with anti-MIP- $1 \alpha$ neutralizing antibody, which were added to culture medium weekly at each medium change. These cultures were compared with LTBMC conducted in standard conditions. In some experiments, LTBMC were also supplemented with a control isotype $\mathrm{IgG}$ and gave similar results compared with cultures without antibody. Treatment of LTBMC with anti-MIP- $1 \alpha$ antibody resulted in decreased growth of BFU-E colonies compared with the no-antibody control culture (165 \pm 33 versus $256 \pm 88, p=0.031)$. However, treatment with recombinant MIP-1 $\alpha$ did not enhance BFU-E growth. Addition of MIP- $1 \alpha$ as well as neutralizing antibody had no effect on CFU-GM in patients and had no effect on LTBMC from normal bone marrow.

\section{DISCUSSION}

We have previously observed in children under CT for ALL a defective erythropoiesis in spite of an adequate erythropoietin production (11). We have also reported that PMN from ALL children under maintenance CT exhibited multiple functional defects, including a depressed microbicidal activity against both Gram-positive and Gram-negative microorganisms (17, 18). In addition, PMN also displayed an accelerated apoptosis that was partially corrected by myeloid growth factors (19). Whether these functional abnormalities result from a direct toxic effect of CT to hematopoietic precursors or are the result of extrinsic factors sensitive to a deleterious effect of CT remains an open question.

CT has been shown to produce prolonged injury to the bone marrow that persists several years after the end of treatment. Quantitative as well as qualitative defects of hematopoietic stem cells and a reduced output of progenitors in LTBMC have been found in patients in long-term remission after aggressive CT regimen (1-6). A direct toxic effect hardly explains a long-term depletion in stem cell pool, as most CT agents are cell cycle-specific and most stem cells are quiescent. In addition, the highest level of the P-glycoprotein efflux conferring resistance to a wide variety of chemotherapeutic agent is observed in human bone marrow cells within cells displaying characteristics of pluripotent stem cells (20). Other authors have raised the possibility of bone marrow microenvironment damage as part of the mechanism of CT-induced hematopoietic toxicity $(9,10,21-23)$.

In this study, we show that, in patients receiving maintenance CT for ALL, there is little change in marrow cellularity and hematopoietic progenitor frequency. By contrast, in these patients, although CFU-GM production is conserved, the 
Table 2a. Effect of TGF- $\beta 1$ neutralization on BFU-E and CFU-GM generated in LTBMC

\begin{tabular}{|c|c|c|c|c|}
\hline & & No antibody & $\begin{array}{l}\text { Anti-TGF- } \beta 1 \text { Ab } \\
(1 \mu \mathrm{g} / \mathrm{mL})\end{array}$ & $P$ \\
\hline \multirow[t]{2}{*}{ CFU-GM } & Normals $(n=6)$ & $6696 \pm 2057$ & $9919 \pm 4521$ & NS \\
\hline & Patients $(n=8)$ & $4641 \pm 766$ & $5030 \pm 1285$ & NS \\
\hline BFU-E & Patients $(n=8)$ & $302 \pm 106$ & $510 \pm 205$ & 0.0078 \\
\hline
\end{tabular}

To determine whether TGF- $\beta 1$ was responsible for the low progenitor production in LTBMC from patients, neutralization experiments were performed. For eight patients and six controls, LTBMC were simultaneously conducted in standard conditions and in presence of anti-TGF- $\beta 1$ antibody, $1 \mu \mathrm{g} / \mathrm{mL}$, that was added to culture each week at the time of medium change. The results represent the mean cumulative number of progenitors generated throughout the culture period and present in stromal layer at the end of culture. The number of BFU-E was significantly increased $(p=0.0078)$ in patient LTBMC supplemented with anti-TGF- $\beta 1$ antibody.

Table 2b. Effect of MIP-1 $\alpha$ neutralization/supplementation on BFU-E and CFU-GM generated in LTBMC

\begin{tabular}{clccc}
\hline & & Anti-MIP-1 $\alpha$ Ab & MIP- $1 \alpha$ \\
$(1 \mu \mathrm{g} / \mathrm{mL})$ & No additive & $2257 \pm 1015$ & $4233 \pm 751$ \\
\hline \multirow{2}{*}{ CFU-GM } & Normals $(n=6)$ & $4419 \pm 2548$ & $2906 \pm 696$ & $2550 \pm 931$ \\
& Patients $(n=6)$ & $2920 \pm 579$ & $7014 \pm 1987$ & $5286 \pm 2531$ \\
BFU-E & Normals $(n=6)$ & $5859 \pm 2106$ & $165 \pm 33 *$ & $268 \pm 92$ \\
& Patients $(n=6)$ & $256 \pm 88$ & NS & 0.031 \\
\hline
\end{tabular}

For six patients and six normal subjects, LTBMC were simultaneously performed in standard conditions, in presence of anti-MIP- $1 \alpha(1 \mu \mathrm{g} / \mathrm{mL})$ or in presence of recombinant human MIP-1 $\alpha(40 \mathrm{ng} / \mathrm{mL})$. Results are expressed as mean cumulative number of progenitors (CFU-GM and BFU-E) generated throughout the LTBMC period, including those present in stromal layer at the end of culture. The number of BFU-E is significantly decreased in patient LTBMC supplemented with anti-MIP-1 $\alpha$ antibody as compared to control LTBMC. * Significant difference as compared to control culture.

BFU-E frequency in LTBMC is markedly reduced compared with controls. These results are slightly different from those observed by others in patients treated with more aggressive therapy regimens, where low frequency of both BFU-E and CFU-GM were observed (4).

Using two-stage LTBMC in which pre-established confluent stromal layers either from patients or normal subjects were inoculated with normal bone marrow $\mathrm{CD}^{+} 4^{+}$cells, patient stroma were found to be defective in their ability to sustain hematopoiesis, as demonstrated by the lower number of BFU-E and CFU-GM generated compared with LTBMC established on stroma from normal subjects. These findings suggest that an important effect of CT in these patients is to induce a defect in bone marrow microenvironment. The fact that LTBMC-derived BFU-E but not CFU-GM are affected by $\mathrm{CT}$, whereas both BFU-E and CFU-GM are reduced in twostage LTBMC using patient stromal layers and healthy CD34 ${ }^{+}$ cells, remains unexplained.

Several drugs used in cancer therapy have been shown to activate stress response signaling pathways, which lead to activation of transcription factors regulating the expression of a wide variety of genes, including those encoding growth inhibitory cytokines such as TGF- $\beta 1$, TNF- $\alpha$, and IL- $1 \alpha$ (24, $25)$. We thus investigated whether inflammatory and growth inhibitory cytokines were released in medium from patient stromal layers in response to CT. Patient SN exerted an inhibitory effect on normal erythroid progenitor cell growth compared with SN from healthy subjects. Immunoassays showed that the levels of IL- $1 \alpha$, TNF- $\alpha$, and IFN- $\gamma$ were undetectable or very low both in patients and controls whereas IL- 6 and SDF- $1 \alpha$ were detected at the same level in both patients and controls. In contrast, TGF- $\beta 1$ levels were significantly higher in patients than in controls. Furthermore, TGF- $\beta 1$ levels in patient cultures were inversely correlated with the number of BFU-E present in the same culture. Anti-
TGF- $\beta 1$ neutralizing antibodies reduced the growth inhibitory activity for erythroid progenitor cells present in $\mathrm{SN}$ of patient LTBMC. This suggests that the inhibitory activity detected in patient LTBMC results, at least in part, from the release of TGF- $\beta 1$ by stromal cells $(26,27)$. The suppressive role of TGF- $\beta 1$ in these cultures is supported by the fact that anti-TGF- $\beta 1$ neutralizing antibody increased significantly BFU-E produced in patient LTBMC. However, TGF- $\beta 1$ neutralization did not restore the same level of BFU-E as in control culture, suggesting that it was not the only mechanism of defective erythropoiesis.

MIP- $1 \alpha$ levels were decreased in SN from patient LTBMC. MIP- $1 \alpha$ is a chemokine that is chemotactic for certain leukocyte subsets. MIP- $1 \alpha$ triggers activation of integrins and has also in vitro and in vivo suppressive effects on hematopoietic stem and progenitor cell proliferation. Taken together, these data imply that MIP- $1 \alpha$ might modulate hematopoiesis by directly influencing adhesion and migration of the hematopoietic progenitor cells through activation of integrin functions. It has been suggested that MIP- $1 \alpha$ may play an important role in maintaining immature hematopoietic progenitors in a quiescent state and protect stem cells from cytotoxicity of cell cyclespecific chemotherapeutic drugs $(13,28)$. This may be in agreement with our results showing that neutralization of MIP- $1 \alpha$ in LTBMC further decreases the number of BFU-E produced throughout the culture period. However, the significance of this observation remains questionable as supplementation of LTBMC with recombinant MIP- $1 \alpha(40 \mathrm{ng} / \mathrm{mL})$ failed to restore the number of progenitor output to normal levels, although this might be related to the propensity of this molecule to polymerize in biologically inactive aggregates (29).

Recent studies have shown that recombinant erythropoietin is effective in preventing CT-induced anemia. However, improvement of anemia is seen only in a half of the patients, even when very high doses are administered $(30,31)$, suggesting 
that in many patients inhibitory factors hinder the action of erythropoietin on progenitors. The present study supports the hypothesis that inhibitors might be produced by bone marrow stroma in response to CT. Consequently, the effectiveness of this therapy might be increased by treatment that aims at correcting the microenvironment dysfunction and/or cytokine imbalance induced by $\mathrm{CT}$ rather than by simply increasing dose of recombinant erythropoietin. Long-term loss of stem cell reserve described by others in cancer patients may be an additional factor explaining the anemia. In this regard, decreased MIP- $1 \alpha$ levels observed during CT might contribute to the loss of immature hematopoietic progenitors.

\section{REFERENCES}

1. Bhavnani M, Morris Jones PH, Testa NG 1989 Children in long-term remission after treatment for acute lymphoblastic leukaemia show persisting haemopoietic injury in clonal and long-term cultures. Br J Haematol 71:37-41

2. Chang J, Geary CG, Testa NG 1990 Long-term bone marrow damage after chemotherapy for acute myeloid leukaemia does not improve with time. $\mathrm{Br} \mathrm{J}$ Haematol 75:68-72

3. Gardner RV, Astle CM, Harrison DE 1997 Hematopoietic precursor cell exhaustion is a cause of proliferative defect in primitive hematopoietic stem cells (PHSC) after chemotherapy. Exp Hematol 25:495-501

4. Soligo D, Lambertenghi Deliliers G, Quirici N, Servida F, Caneva L, Lamorte G 1998 Haematopoietic abnormalities after autologous stem cell transplantation in lymphoma patients. Bone Marrow Transplant 21:15-22

5. Straetmans N, Herman P, Van Bockstaele DR, Michaux L, Hagemeijer A, Ferrant A 1998 Haemopoietic defect and decreased expansion potential of bone marrow autografts from patients with acute myeloid leukemia in first remission. Br J Haematol 101:571-581

6. del Canizo C, Lopez N, Caballero D, Fernandez E, Brufau A, Vazquez L, Mateos V, Gutierrez N, San Miguel JF 1999 Haematopoietic damage persists 1 year after autologous peripheral blood stem cell transplantation. Bone Marrow Transplant 23:901-905

7. Yao M, Bouchet S, Harnois C, Giarratana MC, Laporte JP, Gorin NC, Lopez M, Douay L 1998 Quantitative and qualitative alterations of long-term culture-initiating cells in patients with acute leukaemia in complete remission. Br J Haematol 103:124128

8. Uhlman DL, Verfaillie C, Jones RB, Luikart SD 1991 BCNU treatment of marrow stromal monolayers reversibly alters haematopoiesis. Br J Haematol 78:304-309

9. Galotto M, Berisso G, Delfino L, Podesta M, Ottaggio L, Dallorso S, Dufour C, Ferrara GB, Abbondandolo A, Dini G, Bacigalupo A, Cancedda R, Quarto R 1999 Stromal damage as consequence of high-dose chemo/radiotherapy in bone marrow transplant recipients. Exp Hematol 27:1460-1466

10. Hays EF, Hale L, Villareal B, Fitchen JH 1982 "Stromal" and hemopoietic stem cell abnormalities in long-term cultures of marrow from busulfan-treated Mice. Exp Hematol 10:383-392

11. Corazza F, Beguin Y, Bergmann P, Andre M, Ferster A, Devalck C, Fondu P, Buyse M, Sariban E 1998 Anemia in children with cancer is associated with decreased erythropoietic activity and not with inadequate erythropoietin production. Blood 92:1793-1798

12. Fortunel NO, Hatzfeld A, Hatzfeld JA 2000 Transforming growth factor-beta: pleiotropic role in the regulation of hematopoiesis. Blood 96:2022-2036
13. Verfaillie CM, Catanzarro PM, Li WN 1994 Macrophage inflammatory protein 1 alpha, interleukin 3 and diffusible marrow stromal factors maintain human hematopoietic stem cells for at least eight weeks in vitro. J Exp Med 179:643-649

14. Vilmer E, Suciu S, Ferster A, Bertrand Y, Cavé H, Thyss A, Benoit Y, Dastugue N, Fournier M, Souillet G, Manel AM, Robert A, Nelken B, Millot F, Lutz P, Rialland X, Mechinaud F, Boutard P, Behar C, Chantraine JM, Plouvier E, Laureys G, Brock P, Uyttebroeck A, Margueritte G, Plantaz D, Norton L Francotte N, Gyselinck J, Waterkeyn C, Solbu G, Philippe N, Otten J 2000 Long-term results of the three randomized trials $(58831,58832,58881)$ in childhood acute lymphoblastic leukaemia: a CLCG-EORTC report. Leukemia 14:2257-2266

15. Gartner S, Kaplan HS 1980 Long-term culture of human bone marrow cells. Proc Nat Acad Sci U S A 77:4756-4759

16. Lagneaux L, Delforge A, Dorval C, Bron D, Stryckmans P 1993 Excessive production of transforming growth factor- $\beta$ by bone marrow stromal cells in B-cell chronic lymphocytic leukemia inhibits growth of hematopoietic precursors and interleukin-6 production. Blood 82:2379-2385

17. Lejeune M, Ferster A, Cantinieaux B, Sariban E 1998 Prolonged but reversible neutrophil dysfunctions differentially sensitive to granulocyte colony-stimulating factor in children with acute lymphoblastic leukemia. Br J Haematol 102:1284-1291

18. Lejeune M, Sariban E, Cantinieaux B, Ferster A, Devalck C, Fondu P 1996 Defective polymorphonuclear leukocyte functions in children receiving chemotherapy for cancer are partially restored by recombinant human granulocyte colony-stimulating factor in vitro. J Infect Dis 174:800-805

19. Lejeune M, Cantinieaux B, Harag S, Ferster A, Devalck C, Sariban E 1999 Defective functional activity and accelerated apoptosis in neutrophils from children with cancer are differentially corrected by granulocyte and granulocyte-macrophage colony stimulating factors in vitro. Br J Haematol 106:756-761

20. Chaudhary PM, Robinson IB 1991 Expression and activity of P-glycoprotein, a multidrug efflux pump, in human hematopoietic stem cells. Cell 66:85-94

21. Gibson LF, Fortney J, Landreth KS, Piktel D, Ericson SG, Lynch JP 1997 Disruption of bone marrow stromal cell function by etoposide. Biol Blood Marrow Transplant 3:122-132

22. Mayani H, Guilbert LJ, Janowska-Wieczorek A 1993 Functional characterization of fibroblastic cells in long-term marrow cultures from patients with acute myelogenous leukemia. Leukemia 7:1564-1569

23. Carlo-Stella C, Tabilio A, Regazzi E, Garau D, La Tagliata R, Trasarti S, Andrizzi C, Vignetti M, Meloni G 1997 Effect of chemotherapy for acute myelogenous leukemia on hematopoietic and fibroblast marrow progenitors. Bone Marrow Transplant 20:465-471

24. Newell CL, Deisseroth AB, Lopez-Berestein G 1994 Interaction of nuclear proteins with an AP-1/CRE-like promoter sequence in the human TNF-alpha gene. J Leukoc Biol 56:27-35

25. de Vries P, Singer JW 2000 Lisofylline suppresses ex vivo release by murine spleen cells of hematopoietic inhibitors induced by cancer chemotherapeutic agents. Exp Hematol 28:916-923

26. Migdalska A, Molineux G, Demuynck H, Evans GS, Ruscetti F, Dexter TM 1991 Growth inhibitory effects of transforming growth factor-beta I in vivo. Growth Factors $4: 239-245$

27. Zermati Y, Fichelson S, Valensi F, Freyssinier JM, Rouyer-Fessard P, Cramer E, Guichard J, Varet B, Hermine O 2000 Transforming growth factor inhibits erythropoiesis by blocking proliferation and accelerating differentiation of erythroid progenitors. Exp Hematol 28:885-894

28. Broxmeyer HE, Kim CH 1999 Regulation of hematopoiesis in a sea of chemokine family members with a plethora of redundant activities. Exp Hematol 27:1113-1123

29. Gilmore GL, DePasquale DK, Shadduck RK 1999 Protective effects of BB-10010 treatment on chemotherapy-induced neutropenia in mice. Exp Hematol 27:195-202

30. Cazzola M, Mercuriali F, Brugnara C 1997 Use of recombinant erythropoietin outside the setting of uremia. Blood 89:4248-4267

31. Oberhoff C, Neri B, Amadori D, Petry KU, Gamucci T, Rebmann U, Nowrousian MR, Voigtmann R, Monfardini S, Armand JP, Herrmann R, Netter-Pinon J, TubianaMathieu N, Zwierzina H 1998 Recombinant human erythropoietin in the treatment of chemotherapy-induced anemia and prevention of transfusion requirement associated with solid tumors: a randomized, controlled study. Ann Oncol 9:255-260 